sciendo

\title{
First-order Logic and Some Existential Sentences
}

\author{
Stephen K. McLeod \\ University of Liverpool
}

Disputatio Vol. 4, No. 31

November 2011

DOI: $10.2478 /$ disp-2011-0012

ISSN: 0873-626X 


\title{
First-order logic and some existential sentences
}

\author{
Stephen K. McLeod \\ University of Liverpool
}

\begin{abstract}
'Quantified pure existentials' are sentences (e.g., 'Some things do not exist') which meet these conditions: (i) the verb EXIST is contained in, and is, apart from quantificational BE, the only full (as against auxiliary) verb in the sentence; (ii) no (other) logical predicate features in the sentence; (iii) no name or other sub-sentential referring expression features in the sentence; (iv) the sentence contains a quantifier that is not an occurrence of EXIST. Colin McGinn and Rod Girle have alleged that standard first-order logic cannot adequately deal with some such existentials. The article defends the view that it can.
\end{abstract}

\section{Keywords}

Colin McGinn, existence, existentials, quantification, Rod Girle

\section{Quantified pure existentials}

Existential sentences have stimulated plentiful discussion in logic and ontology. This article draws attention to a less-commonly discussed variety of them, examining its bearing upon logic and, less directly, upon ontology. Let us start with some matters of classification.

Following the notational convention of Palmer (1990: 29), 'EXIST' is an expression for a lexeme, encompassing all forms of the verb. Existential sentences include sentences that feature EXIST (or its counterpart in another language) as a grammatical predicate. Branquinho distinguishes, as follows, between three types of such existential sentences:

(a) Singular existential sentences in which the grammatical predicate 'exist', preceded or not preceded by an expression of negation, is combined with a logically simple singular term, espe-

Disputatio, Vol. IV, No. 31, November 2011

Received on 19 October 2010, and 10 May 2011 
cially a proper name; [e.g.] ... 'Homer exists' and 'Vulcan does not exist'.

(b) Singular existential sentences in which the grammatical predicate 'exist', preceded or not preceded by an expression of negation, is combined with a logically complex singular term, especially a singular definite description; [e.g.] ...'The author of "The Iliad" exists' and 'The tenth planet of the solar system does not exist'.

(c) General existential sentences in which the grammatical predicate 'exist', preceded or not preceded by an expression of negation, is combined with a simple or complex general term (or monadic predicate); [e.g.] ...'Winged mammals exist', 'Unicorns do not exist'. (Branquinho 1998: 5) ${ }^{1}$

Branquinho mentions, but does not classify, such sentences as 'There are no non-existent objects' (Branquinho 1998: 4) and 'There are things which do not exist' (Branquinho 1998: 11). Branquinho does not observe that these sentences do not fall into types (a)-(c). Let me add a fourth type, to which 'There are things which do not exist' belongs. McGinn calls sentences of this fourth type 'unspecific' existentials and he views them as 'test cases for any theory of existence' (McGinn 2000: 28).

(d) A sentence is a quantified pure existential iff it meets all of the following conditions: (i) the verb EXIST is contained in, and is, apart from quantificational BE, the only full (as against auxiliary) verb in the sentence; (ii) no (other) logical predicate features in the sentence; (iii) no name or definite description features in the sentence; (iv) the sentence contains a quantifier that is not an occurrence of EXIST. $^{2}$

E.g.:

(1) Everything exists.

(2) Something exists.

\footnotetext{
${ }^{1}$ The translations are mine.

${ }^{2}$ Quine's notion of a 'pure existential' (Quine 1982: 183) is unrelated.
} 
(3) Some things do not exist.

I do not suggest that types (a)-(d) encompass all existential sentences, or that Branquinho intended types (a)-(c) to do so. 'There are no non-existent objects' does not fall into any of these types, since it does not contain EXIST. Moreover, there are existential sentences which do not employ EXIST or a word that is derived from it. Such sentences include 'There are Germans' and 'Some men are German'. In contrast with sentences of types (a)-(d), it is a matter of some philosophical controversy as to whether sentences like these really are, as Frege 1883? argued, existential.

Adherents of the 'Frege-Russell view' of existence hold that all meaningful sentences of types (a)-(d) are translatable into formulas of standard first-order logic in which ' $\exists$ ', with a variable, captures the logical meaning of EXIST. This stance is a consequence of their view that the use of the quantifier forms a higher-order predicate and that existence is never to be expressed via a first-order predicate. Nevertheless, the thesis that ' $\exists$ ' is an existential (rather than an existentially neutral) quantifier fit for translating all such existential sentences into formulas of standard first-order logic does not entail the FregeRussell view. ${ }^{3}$

Branquinho 1998 observes that sentences of types (b) and (c) fairly readily lend themselves to this sort of translation, whereas sentences of type (a) are more troublesome. ${ }^{4}$ Our current focus, however, is upon type (d) sentences.

\footnotetext{
${ }^{3}$ McGinn and Girle favour what I will call a 'particularist' interpretation of 'some' and its formal analogue ' $\exists$ '. On this view, both 'some' and the symbol used to represent it in a formal language are to be read as existentially neutral. Priest writes: 'what is most naturally called the particular quantifier (being the dual of the universal quantifier) should not be read as "there exists" [...] it should simply be read as some, leaving it open whether the some in question exists or not' (Priest 2008: 42). By 'particularism' I intend the view that the quantifier should be read in the second way. Priest holds further that the quantifier 'should not be read as [...] "there is", there being no real difference between being and existence'. Not everyone who adopts particularism will agree with Priest about that.

${ }^{4}$ Compare Miller (2002: 40), though the account of (neo-)Meinongianism provided by Branquinho (1998: 11-3) shows that Miller is over-optimistic in commenting that 'There is nothing controversial about Russell's treatment of general existential propositions' (Miller 2002: 40).
} 
If we are supposed to symbolize EXIST using ' $\exists$ ', we might be perplexed as to how to translate type (d) existentials into standard firstorder logic. Indeed, some philosophers hold that (at least some) sentences of type (d) cannot adequately be dealt with using the resources of that logic.

While the main aim of McGinn (2000: Chapter 2) is to attack the Frege-Russell view of existence, part of his argument suggests that standard first-order logic is inadequate with respect to type (d) sentences. In relation to (2) ('Something exists'), McGinn writes: 'If we try to translate the sentence in the standard way we get the gibberish, “ $\exists x(x)$ ", with no predicate to write down' (McGinn 2000: 27). Now McGinn (2000: 23, 32-35) holds that it is open to us, in respect of some existentials, to interpret ' $\exists$ ' as having a dual function defined by reference to the particular quantifier 'for some' and the primitive existence predicate 'exists'. However, even this reading of the symbol does not, on his view, afford us the opportunity to formalize type (d) sentences. Rather, he takes it that an adequate formalization of (2) must feature a primitive existence predicate. Translation into standard first-order logic treats all occurrences of EXIST as formalizable using ' $\exists$ ' (interpreted as 'for some') with other symbols, but not including a primitive first-level existence predicate. On McGinn's view that logic, with that approach to translation, leaves us lost for a lexical item that can do the work required to formalize EXIST as it occurs in (2). Of course, as Baumgartner \& Lampert (2008: 103) note, any statement can be rendered into first-order logic by assigning that statement to a sentence letter. This, however, will not result in what they call 'a formal representation of the inner structure' of the statement (Baumgartner \& Lampert 2008: 104). Thus, I interpret McGinn's remark as follows: if we observe standard translational practice, and if (2)'s quantificational-logical form is to be captured, then no well-formed formula of standard first-order logic will be a candidate for being a formalization (whether adequate or otherwise) of (2). Section 2 argues against this position.

According to Girle (2000: 58; 2003: 54), a predicate logic in which the quantifiers are interpreted as having existential import cannot deal adequately with (3): 'The assumption of existential import will just leave us stranded for a translation of "Some things do not exist" (Girle 2000: 58). Girle does not claim that standard firstorder logic has quite the inadequacy in respect of (3) that McGinn appears to associate with (2). Instead, Girle has it that a classical- 
logical approach to (3) will result in a formula that is furnished by classical semantics with a different alethic status to (3) itself. This is the respect in which Girle takes the logic to be inadequate. Section 3 concerns this issue.

\section{Formalizing quantified pure existentials}

For any language of first-order classical logic with identity, either it admits an existence predicate as a defined item of the language's logical vocabulary or it does not. But whether it does or it does not, (3) is formalizable but logically false. (1) and (2) are quantificational truths. Thus, sentences like (1)-(3) do not sustain McGinn's inadequacy charge.

Letting ' $E$ ' be an existence predicate, (1)-(3) are formalizable as:

$(1 *) \forall x[E x]$

$(2 *) \exists x[E x]$

(3*) $\exists x[\sim E x]$

$\left(3^{*}\right)$ is logically false, provided that we treat ' $E$ ' as, like ' $=$ ', part of the logical vocabulary of the language and that we provide it with suitable and classically respectable inference rules or axioms. ${ }^{5}$ Let $L$ be a standard system of classical quantificational logic with identity and without an existence predicate. Obtain $L^{+}$first by supplementing the logical vocabulary of $L$ with ' $E$ '. Then, letting ' $n$ ' range over the individual constants of $L$, supplement the rules of inference of $L$ as follows. ${ }^{6}$

$$
\frac{n=n}{E n}(E-\text {-Introduction })
$$

$$
\frac{E n}{n=n} \text { (E-Elimination) }
$$

The provision of introduction and elimination rules for ' $E$ ' reflects the classical logician's view that the notion of existence is a logical notion. Even with $L^{+}$at our disposal, the classical logician's view that exis-

\footnotetext{
${ }^{5}$ On the admission of an existence predicate into a language of first-order classical logic as part of the logical vocabulary, compare Evans (1982: 345), Branquinho (1998: 26) and Mendelsohn (2005: 104-5).

${ }^{6}$ Compare Nakhnikian and Salmon (1957: 539).
} 
tence is expressed by ' $\exists$ ' is, as we are about to show, by no means under threat. Note, however, that the classical logician need not and does not hold that 'some' in English always has existential import. The word 'and' is an item of logical vocabulary when it expresses truth-functional conjunction. The classical logician need not, and typically does not, suppose that the word 'and' always so functions. Similarly, the word 'some' is an item of logical vocabulary when it functions as a quantifier. When the word 'some' functions as a quantifier, it sometimes has existential import but (as will soon be shown) it does not always have existential import. Indeed, if the classicallogical view required the generalisation that quantificational uses of 'some' always had existential import then the neo-Meinongian's task of refuting the classical-logical view would be way too easy. The classical logician does not and need not make this hard generalisation about natural languages. Producing a sentence in which a quantificational use of 'some' does not have existential import is insufficient to refute the classical-logical view.

Given that we already have existential introduction at our disposal in $L^{+}$, we have the following inference schemata:

$$
\frac{E n}{\exists x[E x]} \quad \frac{n=n}{\exists x[x=n]}
$$

The negation of $\left(3^{*}\right)$ is a theorem of $L^{+}$:

$$
\begin{array}{lll}
-1 . & a=a & =\text {-Introduction } \\
-2 . & E a & 1, E \text {-Introduction } \\
-3 . & \forall x E_{X} & 2, \forall \text {-Introduction } \\
-4 . & \sim \exists_{X}\left[\sim E_{x}\right] & 3, \text { Quantifier Equivalence }
\end{array}
$$

Thus, given the soundness of $L^{+},\left(3^{*}\right)$ is a logical falsehood of $L^{+} .\left(1^{*}\right)$ and $\left(2^{*}\right)$ are logical truths of $L^{+}$.

In a language of first-order classical logic without an existence predicate, a popular method, sometimes known as the 'HintikkaQuine' method, after Hintikka 1966 and Quine 1969, for translating singular existentials involves treating them as existentially quantified identity statements. ${ }^{7}$ Thus, 'Girle exists' is formalized as follows:

\footnotetext{
${ }^{7}$ Compare also Frege 1883? and Nakhnikian and Salmon (1957: 539).
} 
$\exists x[x=g]$. Working in a like manner, (1)-(3) are formalized as follows, each formula having the same alethic status in $L$ as does its counterpart in $L^{+}$:

$$
\begin{aligned}
& (1 * *) \forall x[x=x] \\
& (2 * *) \exists x[x=x] \\
& (3 * *) \exists x[\sim(x=x)]
\end{aligned}
$$

The negation of $(3 * *)$ is a theorem of $L$ :

$$
\begin{aligned}
& \text { - 1. } a=a \\
& =\text {-Introduction } \\
& \text { - 2. } \forall x[x=x] \\
& 1, \forall \text {-Introduction } \\
& \text { - 3. } \sim \exists_{x}[\sim(x=x)]
\end{aligned}
$$

Given the soundness of $L$, the negation of $(3 * *)$ is a logical truth of $L$, so $(3 * *)$ is a logical falsehood of $L .(1 * *)$ and $(2 * *)$ are logical truths of $L .{ }^{8}$

Thus, whether or not we add an existence predicate to standard classical quantificational logic with identity, (3) is formalizable but logically false (provided that we treat the existence predicate as a defined part of the logical vocabulary in the manner indicated above). More generally, (1) and (2) are, on each horn of the dilemma, logically true. For none of (1)-(3) is it the case that when we attempt to translate the sentence we are left without any well-formed formula that is a candidate for being an adequate formalization of the sentence.

\footnotetext{
${ }^{8}$ McGinn notes the 'temptation' to regard 'something exists' and 'something is self-identical' as synonymous (McGinn 2000: 27 note 13) and he observes that on this view $(2 * *)$ is taken to translate (2). McGinn includes among his objections to this the claims that $(2 * *)$ distorts the logical form of (2) and that the synonymy thesis is false. McGinn does not deal with the possibility of providing a translation of $(2)$, as in $(2 *)$, via an existence predicate that is a defined item of the logical vocabulary. The thesis that $(2 *)$ and $(2 * *)$ are logically equivalent, which is weaker than that of synonymy, is what the classical-logical account requires. Since his objections from logical form and from the synonymy thesis do not genuinely threaten the classical-logical account (even though Frege 1883? happened to support the synonymy thesis), the thesis of logical equivalence presents the point at which McGinn's account and the classical-logical account differ. McGinn (2000: Chapters 1 \& 2) has it that all objects are self-identical, but he holds that 'Some things do not exist' is true. I argue otherwise in Section 3.
} 
Taking (2) as an example, it can be granted that $(2 *)$ more closely mirrors the logical form of (2) than does $(2 * *)$. This is of minimal significance to the debate between defenders of a classical-logical approach to type (d) sentences and their opponents. Though they interpret $(2 *)$ differently, neither side in the debate has the monopoly on $\left(2^{*}\right)$ as a formula fit to capture the logical form of (2).

\section{On 'Some things do not exist'}

3.1 To base the claim that 'Some things do not exist' is true on type (c) existentials is to beg the question

Those who take (3) ('Some things do not exist') to be true do so on the basis of such sentences as:

(4) Pegasus does not exist. (Type (a).)

(5) Some characters in works of fiction do not exist. (Type (c).)

This article focusses on the debate about the interpretation of the quantifiers in general sentences. It does not deal in detail with the question of whether negative existentials of type (a) entail (3), though it suggests a negative answer.

Before proceeding to argue, mainly on the basis of considerations that concern general sentences, that (3) is indeed a logical falsehood, I will now argue that there is no type (c) sentence from which (3) can validly be inferred without begging the question on the issue of whether the 'existential' quantifier really has existential import. Consider:

(6) Round squares do not exist.

On the classical view, the inference from (6) to (3) is considered invalid. ${ }^{9}(6)$ is taken to be logically equivalent to

(7) It is not the case that something is a round square.

\footnotetext{
${ }^{9}$ It is not intended to be significant to the argument that follows that it is 'Round squares', rather than say 'Ghosts', that is in the subject-place in (6). 'Round squares' was chosen in order, for rhetorical purposes, to make the argument from (6) to (3) as alike as is possible to an argument that is discussed in the subsection that follows.
} 


\section{$(7 *) \sim \exists_{X}\left[R x \& S_{x}\right]$}

On the classical view, from (7), and so from (6), (3) does not follow.

Though McGinn (2000: 40) is a rare exception, most people on both sides of the debate grant the truth of (6). Assuming that (6) is taken to be true, the claim that the inference from (6) to (3) is valid cannot be used as a point against the classical logician's view of quantification. Rather, the claim to validity begs the question against the classical view since it involves a non-classical interpretation of (6). The theorist who does not admit that something is both round and square has no means to contend that the argument from (6) to (3) is sound. For the particularist, unlike for the classical logician, (6) is (strictly speaking), like 'Andalusians are gregarious', a quantificationally ambiguous sentence containing no quantifier. ${ }^{10}$ The particularist denies that ' $\exists$ ' expresses existence and (typically) denies that EXIST is a quantifier. Accordingly, the particularist must interpret (6) in a manner that accords with either (8) or (9):

(8) All round squares are non-existent.

$\left(8^{*}\right) \forall x\left[\left(R_{x} \& S_{X}\right) \rightarrow \sim E x\right]$

(9) Some round squares are non-existent.

$(9 *) \exists_{x}[(R x \& S x) \& \sim E x]$

If (6) is interpreted along the lines of (8), then so long as the particularist accepts the classical-logical view that 'All $A \mathrm{~s}$ are $B \mathrm{~s}$ ' does not entail 'Some $A \mathrm{~s}$ are $B \mathrm{~s}$ ', the particularist has no available argument from (6) to (3). It is only if the informal interpretation of (6) includes commitment to (9) that it can be claimed that (6) both entails (3) and is true. The premise, so interpreted, cannot be accepted by the classical logician: it begs the question. ${ }^{11}$

Now someone might reason as follows: 'The charge of begging the question cuts both ways. In viewing (6) as translatable using " $\exists$ " and no existence predicate, the classical logician already presumes the falsehood of (3).' This charge is unjustified. From the fact, if it is one,

${ }^{10}$ Compare Branquinho (1998: 11).

${ }^{11}$ Likewise, inferring 'Some things do not exist' from 'Ghosts do not exist' requires an informal interpretation of 'Ghosts do not exist' according to which something is a ghost and non-existent. 
that true negative existentials of type (c) do not entail (3) it does not follow that no sentence does so. Stirton (1995: 40) writes:

It is not hard to see that the usual way of translating existential statements into the predicate calculus will achieve material equivalence in every case only if there are no non-existent objects. Thus ' $\exists$ x.Sx', where ' $\mathrm{S}$ ' means 'santaclausizes', will have the same truth-value as 'Santa Claus exists' only if there is no object which, while not existing, nevertheless santaclausizes. The technical trick of using the existential quantifier to translate existence-statements does not, by itself, prove that there are no non-existent objects; it rather presupposes that there are none.

Stirton's observation that using the existential quantifier (and no primitive existence predicate) as a device for translating all existentials presupposes that (3) is false is correct, since using the existential quantifier (and no primitive existence predicate) for translating type (a) sentences and type (d) sentences presupposes that (3) is false. The classical-logical analysis of type (c) sentences like (6), however, does not of itself require any stance on the issue of whether (3) is true. On the other hand, the point stands that the claim that 'some' and ' $\exists$ ' are existentially neutral in (3) cannot cogently be based on true type (c) sentences like (6).

\subsection{Impossibilia}

'The assumption of existential import', writes Girle, results in the following sentence being ruled to be 'utterly self-contradictory' (Girle 2003: 55):

(10) Some things, such as round squares, are impossible.

Girle does not dwell on the matter, but he appears to be making a rhetorical point in favour of viewing the particular quantifier as existentially neutral. ${ }^{12}$ Girle's claim about the assumption of existen-

\footnotetext{
${ }^{12}$ McGinn (2000: 35) supports the view that the quantifier is existentially neutral. Also, McGinn is 'inclined to take the following line: [some] impossible objects [...] do exist, but what they lack is the possibility of actuality - they are existent entities that could not be actual' (McGinn 2000: 40). This view on impossibilia is not discussed in what follows.
} 
tial import and (10) is correct if (10) is interpreted in a manner that accords with $(10 *)$ :

\section{$(10 *) \exists x[R x \& S x] \& \sim \diamond \exists x[R x \& S x]$}

$\left(10^{*}\right)$ is a logical falsehood in the classically-based quantificational modal logics with reflexive accessibility (i.e., in those normal modal logics which include axiom $(\mathrm{M}): \square A \rightarrow A$ ).

In the absence of a logic for 'such as', and since the belief that (10) expresses a truth that involves none but first-order quantifiers would appear to rest upon inference from 'Round squares are impossible' to 'Some things are impossible', let us consider these two sentences.

(11) Round squares are impossible.

(12) Some things are impossible.

(11) would normally be formalized in quantified modal logic as follows (or as an equivalent formula):

$$
(11 *) \sim \diamond \exists x[R x \& S x]
$$

No existential formula that is a candidate for being a formalization of (12) follows from this. In order to derive one, (11) has to be informally interpreted in a manner that includes commitment to:

(13) Something is round and square, and it is impossible that it exists.

$\left(13^{*}\right) \exists_{x}\left[\left(R_{x} \& S_{X}\right) \& \sim \diamond E_{x}\right]$

$(13 *)$ entails the following formalization of (12):

$$
(12 *) \exists x\left[\sim \diamond E_{x}\right]
$$

When $(11 *)$ is deemed, in this manner, to be an incorrect formalization of (11), it is already taken for granted that ' $\exists$ ' does not express existence. $^{13}$

Now there is a non-literal interpretation of (10) on which the sentence expresses a truth. (10) can be interpreted as equivalent to 'For some Meinongian objects, such as round squares, it is impossible that

\footnotetext{
${ }^{13}$ Compare the discussion of the argument from (6) to (3), in Section 3.1.
} 
those objects exist'. The defender of a classical-logical account of quantification will deny that 'For some' has, at the level of logical form, wide scope here and will deny that 'Meinongian' is a qualifying adjective. Instead, 'Meinongian' is, in this context, transformable into a fictional operator. Thus we have: 'According to Meinongianism, for some objects, such as round squares, it is impossible that those objects exist'. This sentence does not commit us to quantification over round squares or other Meinongian objects and taking it to be true does not require that the classical conception of first-order quantification be relinquished.

(10) was of interest to us primarily because Girle (2003: 55) raised it in the context of his discussion of (3) and because of the parallels between the argument from (11) to (12) and the argument from (6) to (3). If the arguments I have advanced are sound, neither argument is fit to feature in any good critique of the adequacy of standard first-order logic with respect to existentials of type (d).

\section{3 'Some things do not exist' again}

According to Girle, 'If English quantifiers have existential import', then (3) "really" means [...the self-contradictory] At least one existing thing does not exist' (Girle 2003: 54). Though Girle appeals to natural language only here, his remark is readily adaptable, as is suggested by Girle (2000: 58), to the classical-logical approach to (3) set out in Section 2 above.

Girle holds that, contrary to the classical-logical account, (3) 'seems to be a reasonable enough thing to say' (Girle 2000: 58); (Girle 2003: 54). Indeed, he describes (3) as 'perfectly sensible (and true)' (Girle 2003: 55).

In relation to sentences such as (3) and (10), consider the hypothesis that those who are not educated in these matters are sensitive neither to the distinction between objectual and substitutional quantification nor to that between first-order and higher-order quantification. In accordance with this hypothesis, a speaker might endorse, in one context, a claim such as (3) and, in another, one that is (on a first-order, objectual interpretation) inconsistent with it, such as (1) ('Everything exists'). For example, someone might, while endorsing (1), think that (3) is true because they take 'things' in it to range over kinds and they hold that unicorns do not exist. (Formally, they are interpreting (3) as: $\left.\exists F\left[\sim \exists_{X}\left[F_{x}\right]\right].\right)$ The thinkers whose view I am 
opposing, however, are arguing that (3) is a literal truth when its quantifier is interpreted as an objectual, first-order quantifier and that, accordingly, some objects are non-existent (and so (1) is false). Appeal to pre-theoretical intuition about the truth-value of (3) should have little real bearing on whether (3), as (for example) Girle interprets it, is true. While I put little dialectical store by the point, since even those with the most outlandish philosophical views claim common sense to be on their side, the considerations just indicated suggest that the interpretation of (3) as a true sentence involving, as its only quantifier, an occurrence of 'some' that is a first-order quantifier with wide scope is probably distant from common-sense interpretations on which (3) is true.

If someone utters (3) and intends to convey that some things that are purported to exist do not exist then their utterance is not necessarily in conflict with the classical-logical account. To be purportedly a thing is not to be a thing, just as to be a fictional object is not to be an object. The classical logician need not and does not hold that every occurrence of 'Some things' at the start of an English sentence ought to be translated by an occurrence of ' $\exists$ ' plus a variable, since the classical logician, as is familiar, takes it that surface syntax does not always lay bare logical syntax. The exponent of a classical-logical account of first-order quantification can accept as true such sentences as 'Some purported things do not exist' and 'Some characters in works of fiction do not exist': to do so does not entail commitment to quantification over intentional objects, since the classical logician's analysis of the sentences in question will not view 'Some purported things' and 'Some characters in works of fiction', as expressions that really quantify over purported things or characters in works of fiction in these sentences. ${ }^{14}$

One strategy (which I take, with Sainsbury (2005, 2009), to be promising) for accepting these sentences as true invokes fictional operators. It is entailed by sentences in the script for an episode of The Simpsons entitled 'The Regina Monologues', when those sentences are taken literally, that Bart Simpson exists and that Tony Blair exists. ${ }^{15}$ According to 'The Regina Monologues', Tony Blair exists and

\footnotetext{
${ }^{14}$ The objection to which I am responding here was pressed, in discussion, by Kit Fine and John Skorupski.

${ }^{15}$ Source: http://www.cnn.com/2003/SHOWBZ/TV/11/22/blair.simpsons/index.html.
} 
Bart Simpson exists, though in fact Tony Blair exists and it is not the case that Bart Simpson exists.

From 'It is not the case that Bart Simpson exists' (3) does not follow. My reason for thinking this takes us away not from a classicallogical approach to quantification, but from the standard classicallogical account of negation. Where ' $a$ ' is a name, the standard classical account of negation allows for no semantic difference between sentences of the form 'It is not the case that $a$ is $F$ ' and sentences of the form ' $a$ is not $F$ '.

Supposing that 'Some characters in works of fiction do not exist' is true, this does not require the non-existence of some objects. All it requires is the literal falsehood of some grammatically singular existentials that are entailed by the literal interpretations of fictional utterances and works.

The opponent of a classical-logical approach to type (c) sentences might at this stage reason as follows.

Granted, no type (c) sentence can serve as a reason for taking (3) to be true. However, the claim against your favoured analysis of (3) can be weakened as follows. Even if there is no reason whatever to take (3) to be true, it does not follow that (3) is logically false. It is the deeming of (3) as logically false that is objectionable.

I grant that (3) is not as evidently logically false as is, for example

(14) Something is both round and not round.

If (3) were as evidently logically false as (14), then there would be no such debate as the one in which I am engaging. It is worth presenting, then, a final reason for resisting any intuition that (3) is not logically false. Existence can be denied using the expression 'Nothing', as in 'Nothing is both round and square'. Now if 'Something' is existentially neutral then 'Nothing', which is presumably its logical opposite, is presumably also existentially neutral. This, however, conflicts strongly with the fact that existence is often actually denied using the latter expression. 


\title{
4. Conclusion
}

Type (d) sentences that do not involve higher-order quantification are not among the sentences that cannot be rendered into standard firstorder logic. When the quantifiers involved are interpreted as firstorder objectual quantifiers, there is no cogent argument from any type (c) sentence as premise to (3) as conclusion. Negative existentials of type (a) that might be taken to entail (3) may be more problematic. If so then it is those sentences, which have only been considered in passing here, that present standard first-order logic with a genuine problem. Type (d) sentences are not a fruitful resource for employment in arguments for the inadequacy of standard first-order logic with respect to the first-order existentials of natural languages. ${ }^{16}$

\author{
Stephen K. McLeod \\ Department of Philosophy \\ University of Liverpool \\ 7 Abercromby Square \\ Liverpool \\ L69 7WY \\ United Kingdom \\ skmcleod@liv.ac.uk
}

\section{References}

Baumgartner, Michael \& Timm Lampert. 2008. Adequate Formalization. Synthese 164: 93-115.

Branquinho, João. 1998. Acerca da Forma Lógica de Afirmações de Existência. Disputatio Supp. Vol. 1: 4-33.

Evans, Gareth. 1982. The Varieties of Reference. Oxford: Oxford University Press.

\footnotetext{
${ }^{16}$ My work was supported by Spanish Ministry of Science and Innovation research project FFI2009-08828, hosted at the University of Santiago de Compostela, where an earlier version of this article was presented. I am grateful to Xavier De Donato, José Luis Falguera, Concha Martínez, Uxía Rivas, José Miguel Sagüillo, Juan Vázquez and Luis Villegas for their long-standing generosity towards me. For comments on earlier versions I also thank the anonymous referees, Daniel Hill, Jonathan Jones and some members of an audience at the 2008 Mind/Aristotelian Society Joint Session at the University of Aberdeen, namely Kit Fine, David Liggins, Gualtiero Piccinini, John Skorupski and Lee Walters.
} 
Frege, Gottlob. 1883?. Dialog mit Pünjer über Existenz. Unpublished during Frege's lifetime. Reproduced in Hermes, Kambartel \& Kaulbach (1969: 6075). Reprinted in Gabriel (2001: 1-22). Translated by Peter Long \& Roger White as 'Dialogue with Pünjer on Existence', in Hermes, Kambartel \& Kaulbach (1979: 53-67).

Gabriel, Gottfried, ed. 2001. Schriften zur Logik und Sprachphilosophie: Aus dem Nachlaß. Hamburg: Felix Meiner.

Girle, Roderic A. 2000. Modal Logics and Philosophy. Chesham: Acumen.

Girle, Roderic A. 2003. Possible Worlds. Chesham: Acumen.

Hermes, Hans, Friedrich Kambartel \& Friedrich Kaulbach, eds. 1969. Nachgelassene Schriften. Hamburg: Felix Meiner.

Hermes, Hans, Friedrich Kambartel \& Friedrich Kaulbach, eds. 1979. Posthumous Writings. Oxford: Blackwell.

Hintikka, Jaakko. 1966. Studies in the Logic of Existence and Necessity: 1. Existence. The Monist 50: 55-76.

McGinn, Colin. 2000. Logical Properties: Identity, Existence, Necessity, Predication, Truth. Oxford: Oxford University Press.

Mendelsohn, Richard L. 2005. The Philosophy of Gottlob Frege. Cambridge: Cambridge University Press.

Miller, Barry. 2002. The Fullness of Being: A New Paradigm for Existence. Notre Dame, Indiana: University of Notre Dame Press.

Nakhnikian, George \& Wesley C. Salmon 1957. 'Exists' as a Predicate. Philosophical Review 66: 535-542.

Palmer, Frank R. 1990. Modality and the English Modals. 2nd ed., London: Longman.

Priest, Graham. 2008. The Closing of the Mind: How the Particular Quantifier Became Existentially Loaded Behind Our Backs. Review of Symbolic Logic 1: 4255 .

Quine, Willard Van Orman. 1969. Existence and Quantification. In Ontological Relativity and Other Essays. New York: Columbia University Press.

Quine, Willard Van Orman. 1982. Methods of Logic. 4th ed., Cambridge, Massachusetts: Harvard University Press.

Sainsbury, R. Mark. 2005. Reference without Referents. Oxford: Oxford Univeristy Press.

Sainsbury, R. Mark. 2009. Fiction and Fictionalism. London: Routledge.

Stirton, William R. 1995. The Logical Status of 'Exists'. Proceedings of the Aristotelian Society 95: 37-50. 